\title{
Knockdown of Checkpoint Kinase 1 Is Associated with the Increased Radiosensitivity of Glioblastoma Stem-Like Cells
}

\author{
Jun Wu, ${ }^{1}$ Guozheng Lai, ${ }^{1}$ Feng Wan, ${ }^{1}$ Zhengzheng Xiao, ${ }^{1}$ Lingcheng Zeng, ${ }^{1}$ \\ Xiongwei Wang, ${ }^{1}$ Fei Ye ${ }^{1}$ and Ting Lei ${ }^{1}$
}

\author{
${ }^{1}$ Department of Neurosurgery, Tongji Hospital, Tongji Medical School, Huazhong University of Science and \\ Technology, Wuhan Hubei, P.R. China
}

\begin{abstract}
Glioblastoma multiforme is an aggressive brain tumor with a poor prognosis. The glioblastoma stem-like cells (GSCs) represent a rare fraction of human glioblastoma cells with the capacity for multi-lineage differentiation, self-renewal and exact recapitulation of the original tumor. Interestingly, GSCs are more radioresistant compared with other tumor cells. In addition, the remarkable radioresistance of GSCs has been known to promote radiotherapy failure and therefore is associated with a significantly higher risk of a local tumor recurrence. Moreover, the hyperactive cell cycle checkpoint kinase (Chk) 1 and 2 play a pivotal role in the DNA damage response including radiation and chemical therapy. Based on aforementioned, we hypothesized that knockdown of Chk1 or Chk2 might confer radiosensitivity on GSCs and thereby increases the efficiency of radiotherapy. In this study, we knocked down the expression of Chk1 or Chk2 in human GSCs using lentivirus-delivered short hairpin RNA (shRNA) to examine its effect on the radiosensitivity. After radiation, the apoptosis rate and the cell cycle of GSCs were measured with Flow Cytometry. Compared with control GSCs (apoptosis, $7.82 \pm 0.38 \%$; G2/M arrest, $60.20 \pm 1.28 \%$ ), Chk1 knockdown in GSCs increased the apoptosis rate $(37.87 \pm 0.32 \%)$ and decreased the degree of the G2/M arrest $(22.37 \pm 2.01 \%)$. In contrast, the radiosensitivity was not enhanced by Chk2 knockdown in GSCs. These results suggest that depletion of Chk1 may improve the radio-sensitivity of GSCs via inducing cell apoptosis. In summary, the therapy targeting Chk1 gene in the GSCs may be a novel way to treat glioblastoma.
\end{abstract}

Keywords: checkpoint kinase 1; checkpoint kinase 2; glioblastoma stem-like cells; radioresistance; short hairpin RNA Tohoku J. Exp. Med., 2012, 226 (4), 267-274. ㅇ 2012 Tohoku University Medical Press

Glioblastoma multiforme (GBM) is an aggressive neoplasm with a poor prognosis. Despite gross tumor resection or debulking, postoperative radiation therapy and chemotherapeutic treatment, most of the patients died in two years (Laperriere et al. 2002; Combs et al. 2009). Nevertheless, radiotherapy is still one of the most important methods for GBM (WHO IV) (Legler et al. 1999; Bache et al. 2011). Radiation works by damaging the DNA within the tumor cells, making them unable to divide and grow. But the DNA damage checkpoint kinases are hyperactive in glioblastoma stem-like cells (GSCs), which allow cells to be exempted from the DNA damage. The activation of the DNA damage kinases, involved in detecting damaged or abnormally structured DNA, contributes to the radioresistance of GSCs. Compared to non stem-like glioma cells, the GSCs have higher activity of cell cycle checkpoints (Bao et al. 2006). Therefore, GSCs are more resistant to radiation therapy than differentiated tumor cells (Bao et al. 2006; Squatrito et al. 2010). GSCs represent a small sub- population of GBM cells, with the stem-like properties and the capacity of multi-lineage differentiation, self-renewal and exact recapitulation of the original tumor. GSCs play a pivotal role in tumor development and maintenance (Campos et al. 2010; Wan et al. 2010). Because radiation can kill differentiated tumor cells while sparing the rare cancer stem cell population, GSCs are regarded as a "culprit" of tumor recurrence (Bao et al. 2006; Firat et al. 2011). Since the cell cycle checkpoint kinase 1 and 2 (Chk1, Chk2) are the key regulators in cell checkpoint signaling pathway (Smith et al. 2010; Dai and Grant 2010), we hypothesize that restraining Chk1 or Chk2 of GSCs may abrogate cell cycle checkpoint and improve the radiosensitivity. In this study, Chk1 or Chk2 knockdown strategies were employed in exploring whether they can confer radiosensitivity on GSCs. Our data indicate that Chk1 knockdown in GSCs may be a novel strategy for the treatment of glioblastoma.

Received November 28, 2011; revision accepted for publication March 17, 2012. doi: 10.1620/tjem.226.267

Correspondence: Fei YE, M.D., Ph.D., Department of Neurosurgery, Tongji Hospital, Tongji Medical School, Huazhong University of Science and Technology, Wuhan Hubei 430030, P.R. China.

e-mail: dryefei@163.com 


\section{Materials and Methods}

Materials

The human GSC cell line was a gift from Prof. Wan Feng in Tongji Medical College (Campos et al. 2010; Wan et al. 2010). Lentivirus expression vector, pLKO.1-TRC, was obtained from Sigma Company (St. Louis, MO, USA). Restriction endonucleases AgeI, EcoRI, and NcoI and T4 DNA ligase were purchased from NEB Company (Beijing, China). Lentivirus packaging kit was bought from Clontech Company (Osaka, Japan). Fetal bovine serum and DMEM were purchased from Hyclone Company (Logan, UT, USA). Annexin V-FITC kit was bought from BD Company (Franklin Lakes, NJ, USA). Chk1 and Chk2 antibodies were purchased from CST Company (Beverly, MA, USA).

\section{Cell Culture and Identification}

The GSCs were cultured in a serum-free media containing DMEM supplemented with human recombinant epidermal growth factor $(20 \mathrm{ng} / \mathrm{ml})$, basic fibroblast growth factor $(20 \mathrm{ng} / \mathrm{ml})$, leukemia inhibitory factor $(10 \mathrm{ng} / \mathrm{ml})$, and $1 \times \mathrm{B} 27$ without vitamin $\mathrm{A}$ at $37^{\circ} \mathrm{C}$ under $5 \% \mathrm{CO}_{2}$ (Campos et al. 2010). In our study, we identified the GSCs for its stem cell features using neurosphere formation, immunofluorescence and orthotopic xenografting in nude mice. Female BALB/c nude mice (SLAC, Ltd., Shanghai, China), 6 weeks of age, were housed under specific pathogen-free conditions. Animal experimental protocols were approved by Institutional Animal Care and Use Committee, Huazhong University of Science and Technology. Briefly, $1 \times 10^{5}$ cells in $5 \mu$ PBS were implanted stererotactically into the right basal ganglia of the nude mice brain (coordinates: $1.0 \mathrm{~mm}$ forward from bregma, $2.0 \mathrm{~mm}$ lateral, and $3.0 \mathrm{~mm}$ ventral from the dura) using a $10 \mu \mathrm{l}$ Hamilton syringe at a speed of $1 \mu \mathrm{l} / \mathrm{min}$. After harvest, the pathological features of GSCs orthotopic xenografts were identified.

\section{Preparation of short hairpin RNA (shRNA)}

According to the target sequences of Chk1 and Chk2 gene (GenBank GI: 166295195 and 54112406), design interferential sequence Chk1-shRNA and Chk2-shRNA. The Chk1 shRNA sequences were 5'-CCG GCT GCA AAT AGT AGT TCC TGA ACT CGA GTT CAG GAA CTA CTA TTT GCA GTT TTTG-3' (forward) and 5'-AAT TCA AAA ACT GCA AAT AGT AGT TCC TGA ACT CGA GTT CAG GAA CTA CTA TTT GCAG-3' (reverse); the Chk2 shRNA sequences were 5'-CCG GCG CCG TCC TTT GAA TAA CAA TCT CGA GAT TGT TAT TCA AAG GAC GGC GTT TTTG$3^{\prime}$ (forward) and 5'-AAT TCA AAA ACG CCG TCC TTT GAA TAA CAA TCT CGA GAT TGT TAT TCA AAG GAC GGCG-3' (reverse). Oligonucleotides were synthesized by Invitrogen Company (Shanghai, China), and scrambled shRNA sequences served as negative control. These pairs of probes, either the antisense or sense, were dissolved at a concentration of $20 \mu \mathrm{M}$, and the annealing reaction assembled by mixing $5 \mu \mathrm{L}$ of each oligonucleotide with $40 \mu \mathrm{L}$ annealing buffer. The mixture was incubated in PCR Amplifier: $95^{\circ} \mathrm{C}$ for 4 $\min , 70^{\circ} \mathrm{C}$ for $10 \mathrm{~min}$, and then cooling slowly. pLKO.1-TRC vector was linearized with EcoRI and AgeI, then the linearized vector was used directly in a ligation reaction. DH $5 \alpha$ competent cells (Invitrogen, Shanghai, China) of $25 \mu \mathrm{l}$ were transformed using $2 \mu \mathrm{l}$ of ligation mix. The positive clones were selected, verified by electrophoresis pattern, and labeled as pLKO.1-Chk1 and pLKO.1-Chk2. The validity of each construct was confirmed by sequencing analysis
(Invitrogen, Ltd., Shanghai, China).

\section{Generation of Lentiviral Vector}

According to the Lentiviral expressing system user manual, recombinant vector stocks were produced using pLVX-puro plasmid DNA and Lenti-XHT Packaging Mix to transfect 293T cells. The appropriate amount of DNA was diluted in ultra-pure water and obtained the desired transfectate. The transfectate was added to transfect 293 T cells and was removed after 8 hours, and the viral supernatants were collected 48 hours later.

\section{Lentiviral Transduction}

The GSCs were transfered into six well plates and divided into 4 groups, Chk1-shRNA group, Chk2-shRNA group, vector group and untreated group, with two wells in each group. The GSCs were cultured in $900 \mu \mathrm{L}$ medium (contain $4 \mu \mathrm{g} / \mu \mathrm{L}$ polybrene) and $200 \mu \mathrm{L}$ viral supernatants. Eight hours later, culture medium was replaced with normal medium. After 48 hours, the cells were cultured in the medium with $2 \mu \mathrm{g} / \mu 1$ puromycin to select cells that have been transduced with the Lenti-X lentiviruses containing Chk1-shRNA or Chk2-shRNA. Two weeks later, the alive cells were collected and cultured in culture flasks for cell amplification.

\section{Real-time PCR and Western blot analyses}

After transfection, the 5th generations of the GSCs were collected from 4 groups for protein and RNA extraction. Protein concentrations were determined using the BCA protein assay systems (Beyotime Biotech., Haimen, Jiangsu, China), the expressions of Chk1 and Chk2 were detected by Western blot. Chk1 and Chk2 mRNA were detected according to the manufacturer's instruction. The primers for Chk1 and Chk2 were 5'-ATG CTC GCT GGA GAA TTGC-3' (forward) and 5'-ATA AGG AAA GAC CTG TGCGG3'(reverse), and 5'-GCG CCT GAA GTT CTT GTTTC-3' (forward) and $5^{\prime}$-GCC TTT GGA TCC ACT ACCAA-3' (reverse). GAPDH was used as the internal standard in real-time PCR system. The primers for GAPDH were 5'-ACG GAT TTG GTC GTA TTGGG-3' (forward) and 5'-TGA TTT TGG AGG GAT GTCGC-3' (reverse). The results of real-time PCR were analyzed by the $\Delta \Delta \mathrm{Ct}$ method. Each experiment was repeated three times.

\section{Irradiation and Cell Flow Cytometry}

The GSCs were divided into six groups: untransfected group, irradiation group, Chk1-shRNA group, Chk2-shRNA group, irradiation Chk1-shRNA group and irradiation Chk2-shRNA group. An X-ray generator (GE Co., Phil phil DE, CT, USA) was used, and cells were irradiated at room temperature. X-ray-irradiation was performed as single exposure with a dose of 8 Gy. After 48 hours, the apoptosis and cell cycle were analyzed with Flow Cytometry (Becton Dickinson Co., Franklin Lakes, NJ, USA). For apoptosis, the cells were harvested, washed with pre-chilled PBS $\left(4^{\circ} \mathrm{C}\right)$ and adjusted to 1 $\times 10^{5}$ cells $/ \mathrm{ml}$. The cell suspension $(100 \mu \mathrm{l})$ was centrifuged at 1,000 $\times \mathrm{g}$ for $5 \mathrm{~min}$. And then, the supernatant was discarded, the pellet was re-suspended gently in $195 \mu$ l Annexin V-FITC binding buffer and incubated with $5 \mu \mathrm{l}$ Annexin V-FITC in the dark at ambient temperature for $10 \mathrm{~min}$. Cells were then centrifuged at $1,000 \times \mathrm{g}$ for 5 min, and the pellet was re-suspended in $190 \mu \mathrm{l}$ binding buffer. Cells were then incubated with $10 \mu \mathrm{l}$ PI solution $(1 \mu \mathrm{g} / \mathrm{ml})$ on an ice bath in the dark. The suspension of each group was analyzed with Flow Cytometry. For cell cycle analysis with Flow Cytometry, the cells 
were collected into $5 \times 10^{5}$ cell suspension, centrifuged at $900 \mathrm{rpm}$, and then were fixed in $75 \%$ ice ethanol overnight. After washing with $1 \times$ PBS twice, $500 \mu \mathrm{l}$ PI $(1 \mu \mathrm{g} / \mathrm{ml})$ was added to the fixed cells, and incubated for $20 \mathrm{~min}$ at room temperature. Each experiment was repeated three times.

\section{Statistical Analysis}

Statistical analyses were performed using statistical software SPSS 13.0 (SPSS Inc., USA). Data are expressed as $\overline{\mathrm{x}} \pm \mathrm{s}$. Student $T$ test and variance analysis were used in this study. $P<0.05$ was considered as a statistical significant difference.

\section{Results}

Identification of the GSCS

The GSCs used in our study were gifted from Prof. Wan Feng. In a preliminary study, Campos collaborating with Wan Feng and other researchers identified the GSCs and found these cells display classical stem cell features (Campos et al. 2010). We obtained the GSCs used in their study and also identified stem cell properties in this cell line in our lab. As shown in Fig. 1, the GSCs not only express a stem cell marker (CD133) but also reliably form neurospheres and tumors that recapitulate pathological features of human glioblastoma cell xenografts. These results indicate that the GSCs in our study still retain stem cell features.

\section{Chk1 or Chk2 Knockdown in GSCs with Chk1-shRNA or Chk2-shRNA}

The plasmids of pLKO.1-Chk1 and pLKO.1-Chk2 were packed into lentiviral vectors, respectively. The GSCs were infected by the lentivirus and stable transductants were selected based on puromycin resistance. 5 days later, the stably transfected Chk1-shRNA and Chk2-shRNA cells showed regular growth (Fig. 2A). Real-time PCR was used to detect the mRNA expression of Chk1 and Chk2. The expression efficient of Chk1 from the Chk1-shRNA cells was 0.263 , the expression efficient of Chk2 from the Chk2shRNA cells was 0.149 , and the inhibition efficiency were $73.74 \%$ and $85.12 \%$ respectively (Fig. 2B). The protein expression levels of Chk1 and Chk2 were detected by western blot. The Chk1 or Chk2 was significantly down-regulated in stably transfected Chk1-shRNA cells or Chk2shRNA cells (Fig. 2C).

\section{Chk1 Knockdown Facilitates Robust Radiation-induced Apoptosis of GSCs.}

The GSCs were divided into four groups: untreated group, irradiated GSCs (IR) group, irradiated Chk1-shRNA cells, and irradiated Chk2-shRNA cells. GSCs received irradiation at a dose of $8 \mathrm{~Gy}$. After 48-hour incubation, the cell cycle and the apoptosis were analyzed with Flow Cytometry. As shown in Figs. 3, 4 and Table 1, after radiation, $60.20 \pm 1.28 \%$ of GSCs (IR group) displayed G2/M cell cycle arrest and $17.82 \pm 0.38 \%$ displayed apoptosis, while only $22.37 \pm 2.01 \%$ of the irradiated Chk1-shRNA cells were arrested at $\mathrm{G} 2 / \mathrm{M}$ phase and $37.87 \pm 0.32 \%$ displayed apoptosis. Compared with untreated GSCs without radiation $(23.77 \pm 2.31 \%)$, the Chk1-shRNA cells showed no significant difference in the degree of $\mathrm{G} 2 / \mathrm{M}$ cell cycle arrest $(p>0.05)$, indicating that Chk1 knockdown abrogates the radiation-induced G2/M cell cycle arrest in GSCs. In addition, apoptosis and cell cycle analysis showed no significant difference between Chk2-shRNA cells and GSCs after radiation.

\section{Discussion}

Radiation therapy has been employed to treat glioblastoma for many years. However, it has failed to show satisfactory efficacy in clinical practice (Narayana et al. 2012). Potential reason for the inefficacy is the occurence of radioresistance in glioblastoma stem-like cells (Piccirillo and Vescovi 2007; Xie and Chin. 2008). The occurrence of radioresistance, reflected as a diminished susceptibility of the irradiated cells to undergo apoptosis, is a multilateral process regulated by many different factors. Among these factors, in particular, DNA damage repair ability and the cell cycle regulators appear to be a serious hurdle. Radiation to the tumor cells activates multiple DNA damage cell cycle checkpoints (G1, S, G2/M) and then arrests
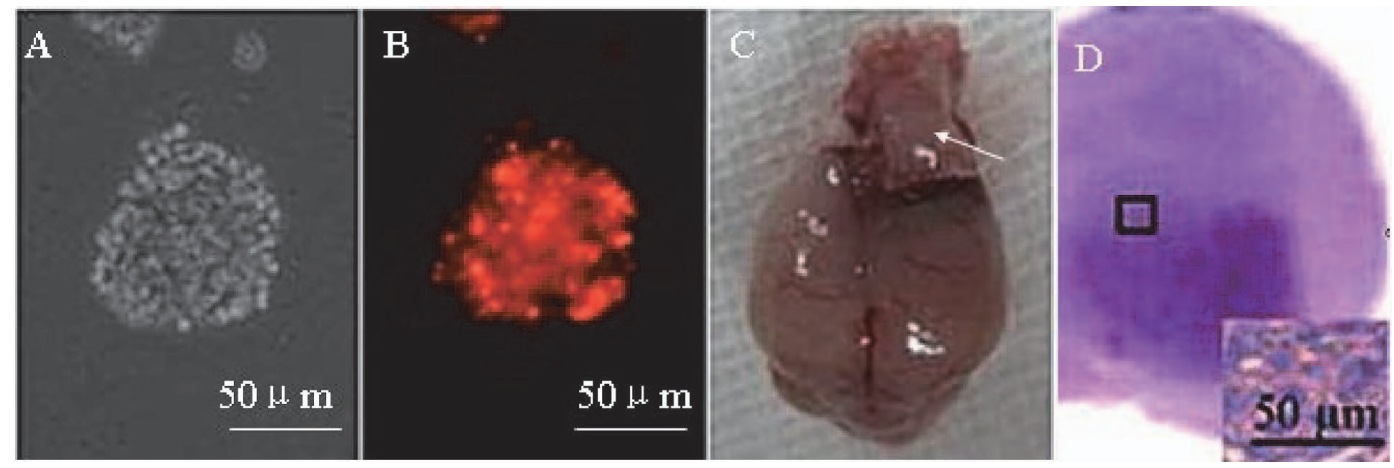

Fig. 1. The stem-like cell features of GSCs used in the present study.

A: The microscopic view of the neurosphere; B: The immunofluorescence shows that the GSCs carry the CD133 surface marker of stem cells; $\mathbf{C}$ : The overall view of mouse brain bearing tumor, 8 weeks after xenotransplantation of $10^{4}$ GSCs. D: The HE staining of mouse brain bearing tumor. 

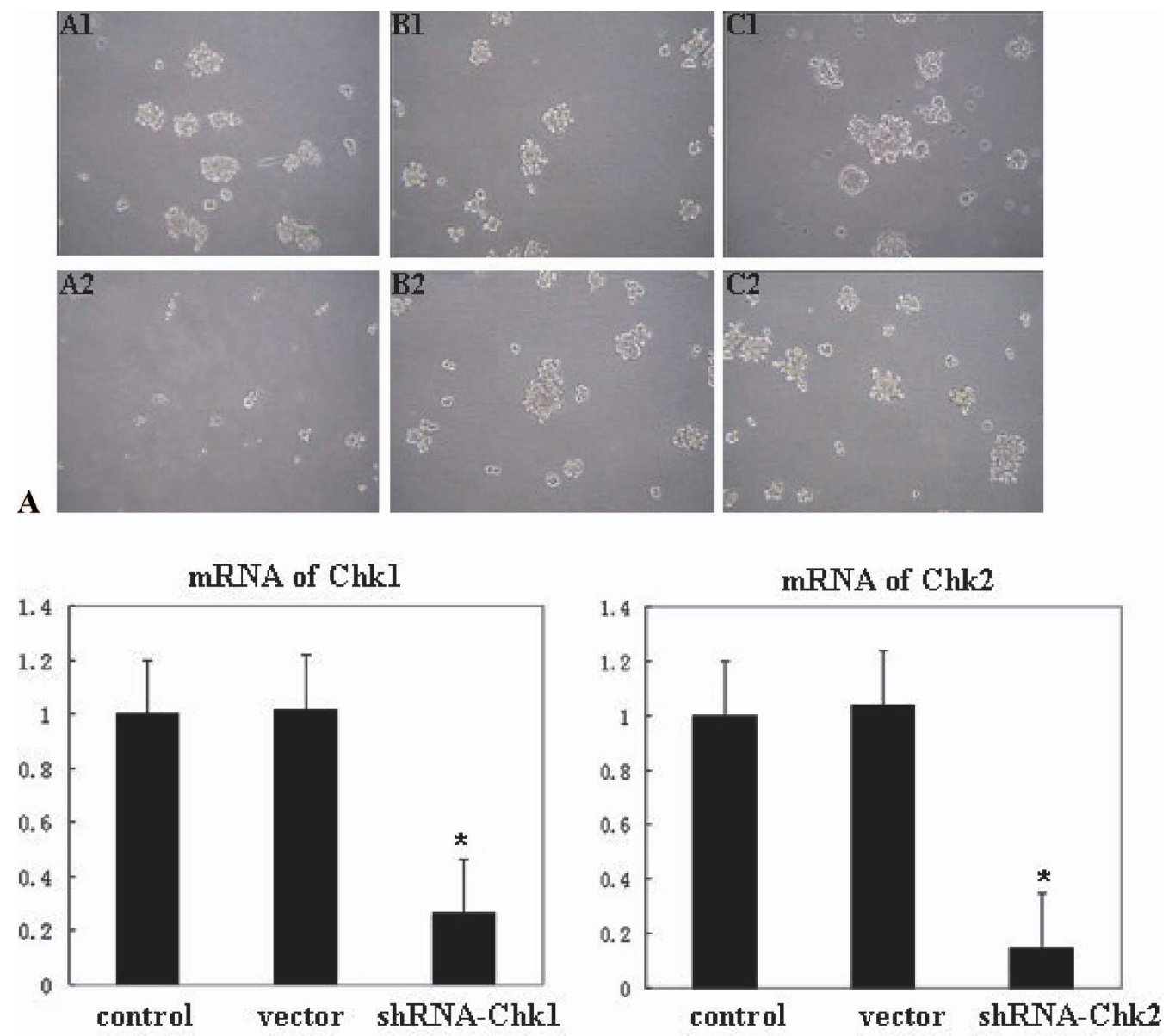

B
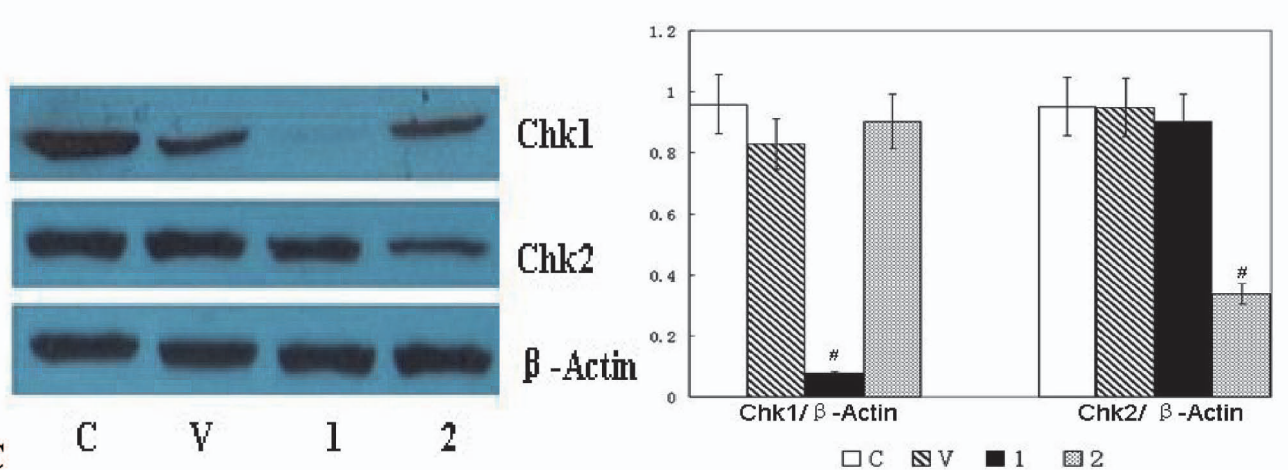

B -Actin

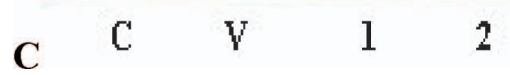

Fig. 2. Knockdown of Chk1 or Chk2 expression by shRNA in GSCs.

A: The microscopic view of cells before and after adding puromycin. Shown are untransfected cells before (A1) and after adding puromycin (A2); Chk1-shRNA cells before (B1) and after adding puromycin (B2); and Chk2-shRNA cells before (C1) and after adding puromycin (C2). B: The relative expression level of Chk1 or Chk2 mRNA was significantly down-regulated in knockdown groups, ${ }^{*} p<0.05$ compared to control and vector groups. There was no significant difference in control group and vector group. The bar represents standard deviation. C: The Chk1 or Chk2 protein expression in different groups of GSCs: C stands for control group, V for vector group, 1 for Chk1-shRNA group, and 2 for Chk2-shRNA group. The bar graphs show the quantitative densitometric analysis of the protein amount of Chk1 or

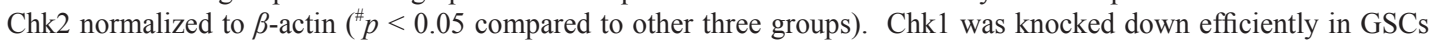
by shRNA transfection. The bar represents standard deviation. Data are one representative of 3 independent experiments.

the impaired cells in the corresponding DNA repair points, which in turn promotes the impaired cells to escape apoptosis, finally leading to the occurrence of the tumor ( $\mathrm{Li}$ et al. 2001; Herman-Antosiewicz et al. 2007; Zachos, et al.
2007). Although, to some extent, the activation of DNA damage cell cycle checkpoints is self-protective, it indeed contributes to tumor recurrence, even in patients received gross resection plus post-operative radiotherapy and che- 


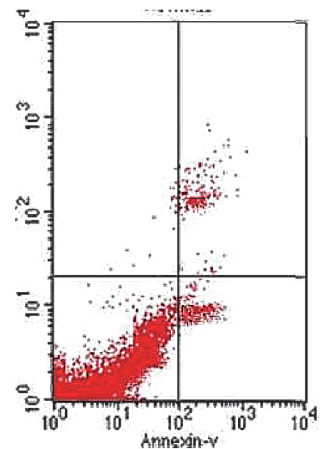

Untreated

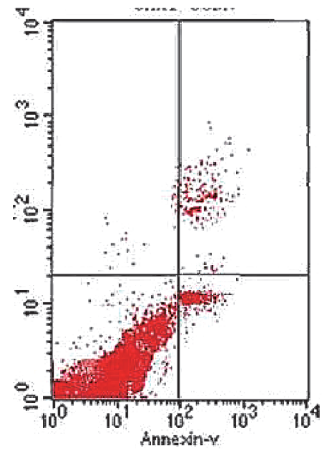

IR

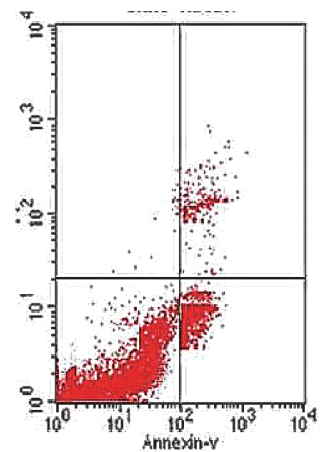

Chk1-shRNA

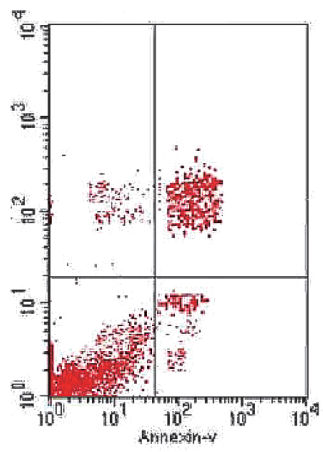

Chk1-shRNA+IR

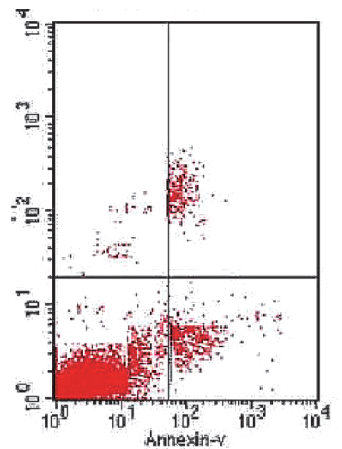

Chk2-shRNA

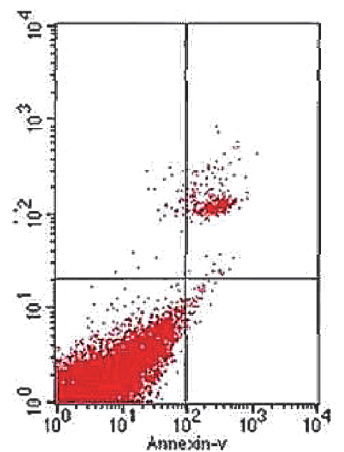

Chk2-shRNA+IR

A

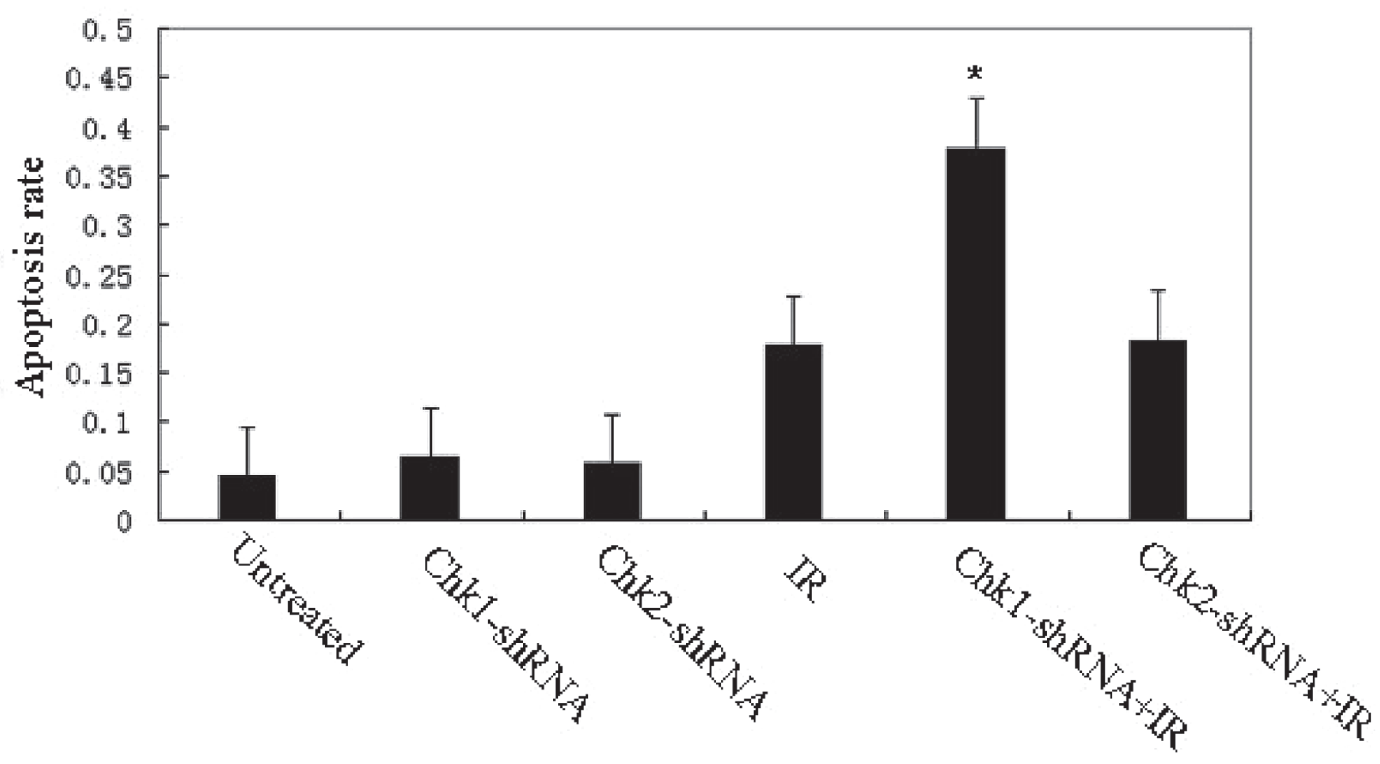

B

Fig. 3. Effect of Chk1 or Chk2 knockdown on the apoptosis of GSCs.

A: Annexin V-FITC assay revealed Chk1 knockdown increased apoptotic rate of GSCs after irradiation (8 Gy). B: The percentage of apoptotic cells. The apoptosis rates were $37.87 \pm 0.32 \%$ in Chk1-shRNA + IR, $18.29 \pm 0.19 \%$ in Chk2shRNA + IR, and $17.82 \pm 0.38 \%$ in IR group. Note the significant increase in apoptosis rate in Chk1-shRNA cells after irradiation ( ${ }^{*} p<0.05$ compared to other groups). The bar represents standard deviation. Data are one representative of three independent experiments.

motherapy.

Besides aforementioned, due to their comparably higher cell cycle checkpoints activity, the GSCs display higher radioresistance than other tumor cells and can survive during the radiation therapy, thereby promoting the tumor recurrence (McCord et al. 2009; Narayana et al. 


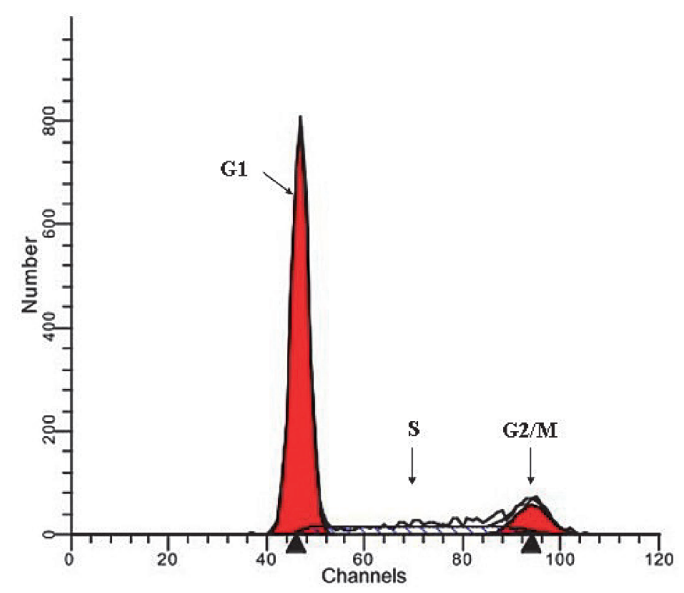

Untreated

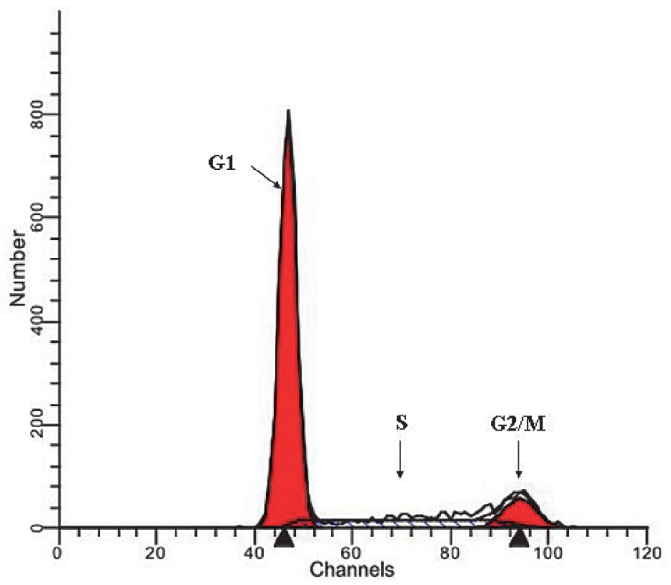

Chk1-shRNA + IR

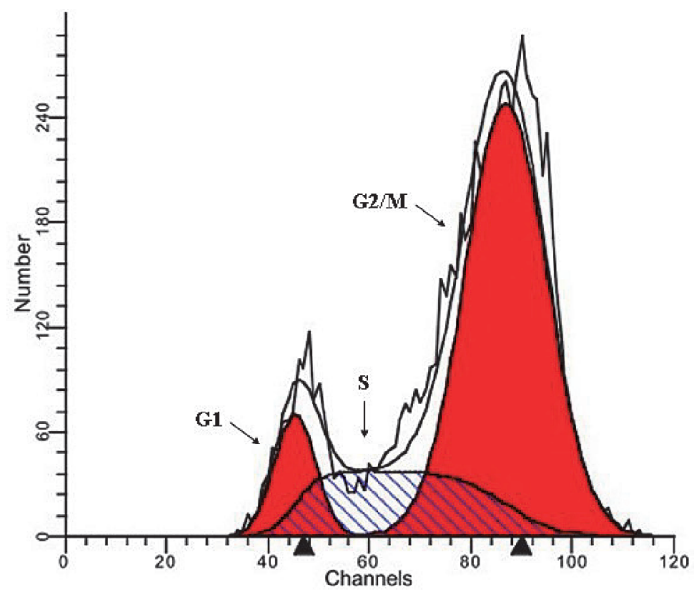

IR

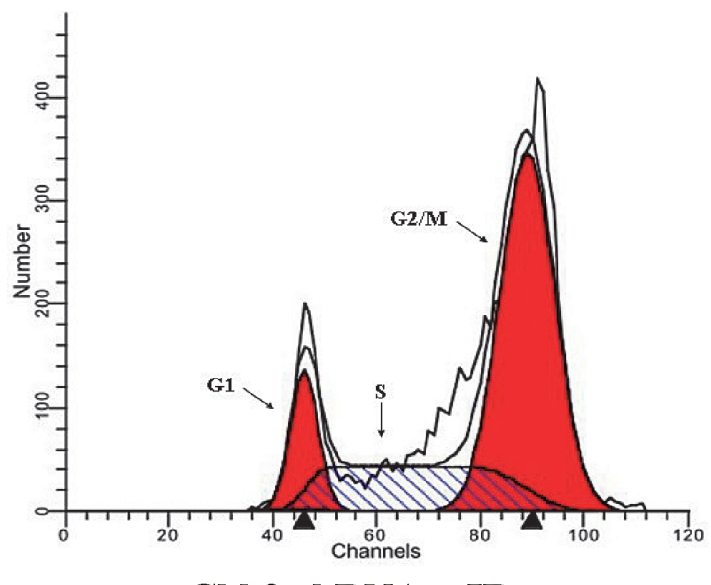

Chk2-shRNA + IR

Fig. 4. Cell cycle analysis of GSCs after irradiation.

After Chk1 or Chk2 knockdown, each group of GSCs was treated with irradiation (8 Gy). After incubation for 24 hours, they were stained with propidium iodide and analyzed by flow cytometry to determine the cell-cycle distribution. The proportion of cells in G2/M phase was significantly increased in IR and Chk2-shRNA + IR groups. On the contrast, Chk1-shRNA + IR group did not show robust cell cycle arrest in G2/M phase. Data are one representative of three independent experiments. G1, S, and G2/M phases were indicated in each panel. The ordinate denotes cell counts and the abscissa represents DNA content.

Table 1. Cell cycle in each group after radiation (48 hour later).

\begin{tabular}{lcrcc}
\hline \multicolumn{1}{c}{ Groups } & G1 (\%) & \multicolumn{1}{c}{$\mathrm{S}(\%)$} & G2/M (\%) & apoptosis (\%) \\
\hline Untreated & $47.09 \pm 1.44$ & $28.09 \pm 2.10$ & $23.77 \pm 2.31$ & $4.51 \pm 0.79$ \\
IR & $25.13 \pm 2.36$ & $9.39 \pm 1.47$ & $60.20 \pm 1.28$ & $17.82 \pm 0.38$ \\
Chk1-shRNA + IR & $55.24 \pm 1.34$ & $19.06 \pm 1.38$ & $22.37 \pm 2.01 *$ & $37.87 \pm 0.32^{\#}$ \\
Chk2-shRNA + IR & $30.59 \pm 2.46$ & $8.29 \pm 0.98$ & $58.08 \pm 1.37$ & $18.29 \pm 0.19$ \\
\hline
\end{tabular}

Note that the number of cells in G2/M phase was significantly decreased in Chk1-shRNA + IR group $\left({ }^{*} p<\right.$ 0.05 , compared with IR and Chk2-shRNA + IR groups). The apoptosis rate was significantly increased in Chk1shRNA + IR group ( ${ }^{*} p<0.05$, compared with IR, Chk2-shRNA + IR and Untreated groups). Data shown are means \pm S.D. of three independent experiments. IR stands for irradiation.

2012). Furthermore, the GSCs contribute to glioma radioresistance through preferential activation of the DNA damage checkpoint response and increasing DNA repair capacity (Bao et al. 2006). Based on these reasons, we hypothesized that increasing radiation sensitivity of GSCs might improve the curative effect of malignant glioma. Because the cell cycle checkpoint pathways have been shown to play a vital role in the development of radioresistance in tumor cells (McCord et al. 2009; Narayana et al. 2012), in this study, we explored the role of knockdown 
strategy targeting the cell cycle checkpoint pathways in glioblastoma radiotherapy.

Chk1 and Chk2, two numbers of serine/threonine kinase of family, are key regulators in the DNA damage response (Zhou et al. 2003; Kastan and Bartek 2004). Chk1 and Chk2 have been shown to be involved in multiple checkpoint pathways, including the S phase and G2/M phase regulating pathway (Zhou and Bartek 2004; Wang et al. 2004). In addition, Chk 1 and Chk 2 may be associated with the occurrence of glioma (Sancer et al. 2004). Moreover, previous studies reported that loss of Chk1 sensitizes tumor cells to many anticancer agents (Wang et al. 2004; Sidi et al. 2008; Monica et al. 2008; Morgan et al. 2010). All these above mentioned suggest the key role of Chk1 and Chk2 enzymes in the cell cycle checkpoints activation, which in turn promotes the DNA damage repairing (Bao et al. 2006), thereby preventing the cells from radiation and chemical therapy associated death. Based on these reasons, we speculated that the therapy targeting Chk1 or Chk2 might be a novel way to interfere the cell cycle checkpoint pathway, which in turn improve sensitivity of radiotherapy and chemotherapy.

In this study, the apoptosis of GSCs was set as the radiosensitivity parameter (McMillan et al. 2001). Furthermore, lentiviral Chk1 or Chk2 shRNA transfection can knockdown the expression of Chk1 or Chk2 mRNA. In addition, the Chk1-shRNA cells displayed elevated apoptosis rate and lower rate of $\mathrm{G} 2 / \mathrm{M}$ cell cycle arrest, whereas the apoptosis and cell cycle analysis failed to find significant difference between Chk2-shRNA GSCs and normal GSCs. Our results are in line with previous studies, which have reported that Chk1 plays a key regulatory role in the G2/M DNA damage checkpoint (Zachos et al. 2005; Zachos et al. 2007). Besides Chk1, Chk2 has also been shown to be involved in the DNA damage signal transduction of the G1 and G2/M checkpoints, which is varied from Chk1 (Ahn et al. 2003; Varmark et al. 2010). Our study showed that knockdown of Chk2 does not sensitize cells to anticancer radiation, which is consistent with previous studies (Carrassa et al. 2004). In order to further explore the underlying mechanisms, we have done relative mechanistic studies and found that shRNA transfection of Chk1 but not Chk2 abolishes the radioresistance via the G2 arrest, sensitizing the GSCs to apoptosis following radiation. We also have tried to knock down Chk1 and Chk2 in GSCs by lentivirus transfection, however, when we knocked down the Chk1 and Chk2 in GSCs simultaneously, the cells did not proliferate and almost all the cells were eventually dead. So we had to abandon this strategy to deplete Chk1 and Chk2 simultaneously in our study. The failure of this strategy may be due to our skills, oligonucleotides and reagents of the lentivirus transfection system or to the nature of cell line itself.

In this study, our results indicate that Chk1 knockdown may improve the sensitivity of GSCs in radiotherapy via attenuating DNA damage checkpoint and increasing cell apoptosis, suggesting that Chk1 may be a novel target in glioblastoma treatment. There is an inherent limitation of our experimental results, as apoptosis is not the only form of cell death, it is possible that shRNA-Chk1 and/or 2 may sensitize cells to IR or chemical therapy via promoting other modes of cell death but not apoptosis, such as necrosis. In addition, because Chk 2 was only partially decreased in our study, our studies can not exclude the possibility that fully Chk2 inhibition may also exert radiosensitizing effect. However, recent evidence suggested that inhibition of Chk2 did not produce sensitization and depletion of Chk2 or Chk2 siRNA did not increase the radiosensitization (Morgan et al. 2010). Taken together, these aforementioned suggest that it is the inhibition of Chk1 but not Chk2 that increases the radiosensitization in GSCs. Due to the complex biological properties of chemical and/or radio resistance, further studies are highly warranted.

\section{Acknowledgments}

The authors would like to thank all participants for their cooperation. This study was supported by the Foundations from National Natural Science Foundation of China (No. 30901749, No. 30801177).

\section{Conflict of Intrerest}

All authors declare no conflict of interest.

\section{References}

Ahn, J., Urist, M. \& Prives, C. (2003) Questioning the role of checkpoint kinase 2 in the p53 DNA damage response. $J$. Biol. Chem., 278, 20480-20489.

Bache, M., Zschornak, M.P., Passin, S., Kessler, J., Wichmann, H., Kappler, M., Paschke, R., Kaluderovic, G.N., Kommera, H., Taubert, H. \& Vordermark, D. (2011) Increased betulinic acid induced cytotoxicity and radiosensitivity in glioma cells under hypoxic conditions. Radiat. Oncol., 6, 111-120.

Bao, S., Wu, Q., McLendon, R.E., Hao, Y., Shi, Q., Hjelmeland, A.B., Dewhirst, M.W., Bigner, D.D. \& Rich, J.N. (2006) Glioma stem cells promote radioresistance by preferential activation of the DNA damage response. Nature, 444, 756-760.

Campos, B., Wan, F., Farhadi, M., Ernst, A., Zeppernick, F., Taqscherer, K.E., Ahmadi, R., Lohr, J., Dictus, C., Gdynia, G., Combs, S.E., Goidts, V., Helmke, B.M., Eckstein, V., Roth, W., Beckhove, P., Unterberg, A., Radlwimmer, B. \& HeroldMende, C. (2010) Differentiation therapy exerts antitumor effects on stem-like glioma cells. Clin. Cancer Res., 16, 27152728.

Carrassa, L., Broggini, M., Erba, E. \& Damia, G. (2004) Chk1, but not Chk2, is involved in the cellular response to DNA damaging agents: differential activity in cells expressing or not p53. Cell Cycle, 3, 1177- 1181.

Combs, S.E., Bohl, J., Elsasser, T., Weber, K.J., Schulz-Ertner, D., Debus, J. \& Weyrather, W.K. (2009) Radiobiological evaluation and correlation with the local effect model (LEM) of carbon ion radiation therapy and temozolomide in glioblastoma cell lines. Int. J. Radiat. Biol., 85, 126-137.

Dai, Y. \& Grant, S. (2010) New insights into checkpoint kinase 1 in the DNA damage response signaling network. Clin. Cancer Res., 16, 376-383.

Firat, E., Gaedicke, S., Tsurumi, C., Esser, N., Weyerbrock, A. \& Niedermann, G. (2011) Delayed cell death associated with mitotic catastrophe in $\gamma$-irradiated stem-like glioma cells. 
Radiat. Oncol., 6, 71-85.

Gao, Q., Zhou, J., Huang, X., Chen, G., Ye, F., Lu, Y., Li, K., Zhuang, L., Huang, M., Xu, G., Wang, S. \& Ma, D. (2006) Selective targeting of checkpoint kinase 1 in tumor cells with a novel potent oncolytic adenovirus. Mol. Ther., 13, 928-937.

Herman-Antosiewicz, A., Stan, S.D., Hahm, E.R., Xiao, D. \& Sinqh, S.V. (2007) Activation of anvel ataxia-telangiectasia mutated and $\operatorname{Rad} 3$ related/checkpoint kinase 1-dependent prometaphase checkpoint in cancer cells by diallyl trisulfide, a promising cancer chemo preventive constituent of processed garlic. Mol. Cancer Ther., 6, 1249-1261.

Kastan, M.B. \& Bartek, J. (2004) Cell-cycle checkpoints and cancer. Nature., 18, 316-323.

Laperriere, N., Zuraw, L. \& Cairncross, G. (2002) Radiotherapy for newly diagnosed malignant glioma in adults: a systematic review. Radiother. Oncol., 64, 259-273.

Legler, J.M., Ries, L.A., Smith, M.A., Warren, J.L., Heineman, E.F., Kaplan, R.S. \& Linet, M.S. (1999) Brain and other central nervous system cancers: recent trends in incidence and mortality. J. Natl. Cancer Inst., 91, 1382-1390.

Li, L., Story, M. \& Legerski, R. (2001) Cellular responses to ionizing radiation damage. Int. J. Radiat. Oncol. Biol. Phys., 49, 1157-1162.

McCord, A.M., Jamal, M., Willams, E.S., Camphausen, K. \& Tofilon, P.J. (2009) CD133 ${ }^{+}$Glioblastoma Stem-like Cells are Radiosensitive with a Defective DNA Damage Response Compared with Established Cell Lines. Clin. Cancer Res., 15, 5145-5153.

McMillan, T.J., Tobi, S., Mateos, S. \& Lemon, C. (2001) The use of DNA doublestrand break quantification in radiotherapy. Int. J. Radiat. Oncol. Biol. Phys., 49, 373-377.

Monica, G., Laura, C., Francesca, C., Michele, T., Massimo, B. \& Giovanna, D. (2008) Checkpoint kinase 1 down-regulation by an inducible small interfering RNA expression system sensitized in vivo tumor to treatment with 5-fluorouracil. Clin. Cancer Res., 14, 5131-5141.

Morgan, M.A., Parsels, L.A., Zhao, L., Parsels, J.D., Davis, M.A., Hassan, M.C., Arumugarajah, S., Hylander-Gans, L., Morosini, D., Simeone, D.M., Canman, C.E., Normolle, D.P., Zabludoff, S.D., Maybaum, J. \& Lawrence, T.S. (2010) Mechanism of radiosensitization by the Chk $1 / 2$ inhibitor AZD7762 involves abrogation of the G2 checkpoint and inhibition of homologous recombinational DNA repair. Cancer Res., 70, 4972-4981.

Narayana, A., Gruber, D., Kunnakkat, S., Golfinos, J.G., Parker, E., Raza, S., Zagzag, D., Eagan, P. \& Gruber, M.L. (2012) A clinical trial of bevacizumab, tmozolomide, and radiation for newly diagnosed glioblastoma. J. Neurosurg., 116, 341-345.
Piccirillo, S.G. \& Vescovi, A.L. (2007) Brain tumor stem cells: possibilities of new therapeutic strategies. Expert Opin. Biol. Ther, 7, 1129-1135.

Sancer, A., Lindsey-Boltz, L.A., Unsal-Kacmaz, K. \& Linn, S. (2004) Molecular mechanisms of mammalian DNA repair and DNA damage checkpoints. Annu. Rev. Biochem., 73, 39-45.

Sidi, S., Sanda, T., Kennedy, R.D., Haqen, A.T., Jette, C.A., Hoffmans, R., Pascual, J., Imamura, S., Kishi, S., Amatruda, J.F., Kanki, J.P., Green, D.R., D’Andrea, A.A. \& Look, A.T. (2008) Chk1 suppresses a caspase-2 apoptotic response to DNA damage that bypasses p53, Bcl2, and Caspase-3. Cell, 133, 864-877.

Smith, J., Tho, L.M., Xu, N. \& Gillespie, D.A. (2010) The ATM-Chk2 and ATR-Chk1 pathways in DNA damage signaling and cancer. Adv. Cancer Res., 108, 73-112.

Squatrito, M., Brennan, C.W., Helmy, K., Huse, J.T., Petrini, J.H. \& Holland, E.C. (2010) Loss of ATM/Chk2/p53 pathway components accelerates tumor development and contributes to radiation resistance in gliomas. Cancer Cell, 18, 619-629.

Varmark, H., Kwak, S. \& Theurkauf, W.E. (2010) A role for Chk2 in DNA damage induced mitotic delays in human colorectal cancer cells. Cell Cycle, 9, 312-320.

Wan, F., Zhang, S., Xie, R., Gao, B., Campos, B., Herold-Mende, C. \& Lei, T. (2010) The utility and limitations of neurosphere assay, CD133 immunophenotyping and side population. Brain Pathol., 20, 877-889.

Wang, Y., Decker, S.J. \& Sebolt-Leopold, J. (2004) Knockdown of Chk1, Wee1 and Myt1 by RNA interference abrogates G2 checkpoint and induces apoptosis. Cancer Biol. Ther., 3, 305313.

Xie, Z. \& Chin, L.S. (2008) Molecular and cell biology of brain tumor stem cells: lesions from neural progenitor/stem cells. Neurosurg. Focus, 24, E24.

Zachos, G., Black, E.J., Walker, M., Scott, M.T., Vaqnarelli, P., Earnshaw, W.C. \& Gillespie, D.A. (2005) Chk1-dependent $\mathrm{S}-\mathrm{M}$ checkpoint delay in vertebrate cells is linked to maintenance of viable replication structures. Mol. Cell. Biol., 25, 563-574.

Zachos, G., Black, E.J., Walker, M., Scott, M.T., Vaqnarelli, P., Earnshaw, W.C. \& Gillespie, D.A. (2007) Chk1 is required for spindle checkpoint function. Dev. Cell, 12, 247-260.

Zhou, B.B., Anderson, H.J. \& Roberge, M. (2003) Targeting DNA checkpoint kinases in cancer therapy. Cancer Biol. Ther., 2, 16-22.

Zhou, B.B. \& Bartek, J. (2004) Targeting the checkpoint kinases: chemosensitization versus chemoprotection. Nat. Rev. Cancer, 4, 216-225. 